ELK ASIA PACIFIC JOURNAL OF SOCIAL SCIENCES

ISSN 2394-9392 (Online); DOI: 10.16962/EAPJSS/issn.2394-9392/2014; Volume 2 Issue 3 (2016)

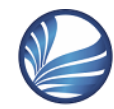

ELK

Asia Pacific Journals

$\underline{\text { www.elkjournals.com }}$

\title{
AN INVESTIGATIVE STUDY ON EFFECTIVENESS OF PROGRAMS REDUCING HIGH SCHOOL DROP-OUTS IN SOUTH INDIA-A CASE OF ADILABAD DISTRICT OF TELANGANA
}

\author{
B.Laxmaiah \\ M.A, M.Ed, M.Phil, Research Scholar, \\ OPJS University, Churu, Rajasthan
}

\author{
Dr. Gurmeet Singh Kachoora \\ M.A, M.Ed, PhD, \\ OPJS University, Churu, Rajasthan
}

\begin{abstract}
The purpose of this review paper was to conduct an investigative study on effectiveness of programs reducing high school dropouts in Adilabad district of Telangana, specifically with evaluating the effectiveness of programs of Government of India and State Government of Telangana in reducing high school dropouts. For achieving the purpose of the study only secondary research has been conducted using main secondary sources in the forms of journals, newspapers, governmental and non-governmental reports. The findings of the study reveal that the population of Adilabad is largely dependent on farming and therefore income certainty forces parents to get their daughters married off premature. Education can play a decisive role in dallying child marriages, but girl child generally dropout from the schools indicating towards the apathy of school managements in Adilabad. Cases reveal that as soon as the girls enter school parents start planning to get them into wedlock. Furthermore in the case of Adilabad district migration appears to be main cause of school dropout. In the case of dropout of girl children majority of them are engaged in domestic works and for looking after the children. The State Government of Telangana is failing to resolve these problems relating to school dropout and as a result the situation is truing from worse to worst. Therefore it would be suggestive for the government in order to reduce the secondary school dropout immediate measure should be taken as regards the identified problems. Reducing dropout in secondary education is the need of the hour in a bid to protecting, nourishing and equipping children with needed skill for empowering India in terms of skilled and competent human resources.
\end{abstract}

Keywords: Adilabad, Telangana, Drop out, School, Children, Education

\section{Introduction}

In Telangana state of India school dropout rate is very high portraying a very pitiable situation of secondary education in the state in the context of school dropout rate. The most pitiable condition is in the districts of Mahbubnagar, Medak, Warangal and
Adilabad with the dropout rate of $53.21 \%$, $47.28 \%, 43.03 \%$ and $42.12 \%$ (Mukaa, 2014). Even though the situation of Mahbubnagar is the worst in terms of dropout at secondary level, but the case of Adilabad is not less pitiable specifically in the context of girls' dropout in high schools. 


\section{ELK ASIA PACIFIC JOURNAL OF SOCIAL SCIENCES}

ISSN 2394-9392 (Online); DOI: 10.16962/EAPJSS/issn.2394-9392/2014; Volume 2 Issue 3 (2016)

About half of the students enrolled in school ends as dropout. Several programs have been implemented by the Government of India and the State Government to reduce the dropout rate, but taken as a whole the results are not enthusiastic. In the background of these facts and figures, this paper conducts an investigative study on effectiveness of programs reducing high school drop-outs in Adilabad district of Telangana. The paper firstly conceptualizes the concept of school dropout with reference to the definitions and concepts extended by the recognsied social scientists. Further the problem of dropout is critically discussed on all India level with reference to the effectiveness of Government of India programs implemented to control dropout and bring back children to school. Next is the main part of this study, which investigates the high school or secondary education dropout rate in Telangana and specifically with evaluating the effectiveness of programs of Government of India and State Government of Telangana in reducing high school dropouts. For conducting the study only secondary sources have been used. The main secondary sources have been used in the forms of journals, newspapers, governmental and non-governmental reports. Whilst using secondary sources data have been gathered in both quantitative and qualitative forms.

\section{School Dropout Concept}

Dropout is defined as the children proportion ceasing to continue enrolled in the school. Social scientists and analysts across the world have broadly investigated the reasons of dropouts. This is in the light of the fact that dropout problem has turned out to be a concern worldwide for the policy makers of school education system. At the global level, Weber (1988) and Rumberger(2011) classify the reasons for school dropouts into three kinds that is to say problems related to family, problems related to school and personal problems. Some main family related problems are found related to the poor socio-economic position, deprived groups, low level of parental education and solo parent families. Furthermore, a few school related problems are identified in the forms of the attendance, grades, academic accomplishment, interest in school and school work. When it comes to personal reasons of dropout they are found mainly in the forms of problems related to discipline and extenuating problems comprising marriage etc. 


\section{ELK ASIA PACIFIC JOURNAL OF SOCIAL SCIENCES}

ISSN 2394-9392 (Online); DOI: 10.16962/EAPJSS/issn.2394-9392/2014; Volume 2 Issue 3 (2016)

\section{Case of India}

In most of the developing countries, population is increasing with fast rate having a high percentage of children. The grown-up population in these countries mostly is failing to get required educational facilities and training together with additional social amenities resulting high dropout in secondary education. Governments in developing countries are under constant pressure implementing effective programs bringing forward to resolve the problems of high dropout in schools, particularly in secondary schools where growing-up populace study. Besides the problem of dropout ought to be tackled at the family level too. Moreover, there requires a comprehensive social awareness program to be launched to persuade parents to stand their children's interest, attitude and ambition level to higher education, good jobs and better life(Alagusundaram, Sivakumar and Rajendraprasad, 2015).

In Indian education system, dropout is a universal problem, spread over every level of education, in the entire country and across every socio-economic group of populace. However, in educationally backward states and districts the dropout rates are much higher. Besides, girls' dropout rates are found rather higher than the boys in India (Chug, 2011). The school education system in India is experiencing with high frequency of dropout at secondary or high school level mainly 6th to 8th classes and the problem of dropout is graver at girls' level than boys' level. The data reveals that in India girls' dropout is higher than boys' dropout, resulting in a widening of the gender gap between primary and secondary and amid secondary and tertiary enrolment ratios (Alagusundaram, Sivakumar and Rajendraprasad, 2015). Dropout in secondary education is alarming in India. Specifically in the age group of 15-18 years, 40 to $50 \%$ of the children are dropping out of schools notwithstanding State governments claiming to afford them required support through various policies and programs (Vidyasagar, 2015). As far as the reasons of higher dropouts in India are concerned Chug (2011) finds that largely family and school related problems are the main reasons why dropout is higher in secondary or high school education in India. More exactly, poverty and fiscal constraints are indeed, at the same time as schools not responding applicably to students special educational requirements force them to dropout. 


\section{ELK ASIA PACIFIC JOURNAL OF SOCIAL SCIENCES}

ISSN 2394-9392 (Online); DOI: 10.16962/EAPJSS/issn.2394-9392/2014; Volume 2 Issue 3 (2016)

Analysing National Family Health Survey-3

Data, Gouda and Sekhe(2014 ) find that the main reasons of school dropout in India are children not interested in studies, high cost of schooling, requirement to involve in household works, and contributing in family income doing work. Specifically in the case of girl students it is found that their dropout from the high school is mainly because of getting married. Precisely, when it comes to household reasons of school dropout, the study reveals that nearly half (46\%) of the total dropouts is because of household reasons in the forms of doing household work and contributing in the family income. when it comes to the school related reasons, the study reveals that poor infrastructure, lack of teachers, are the main reasons contributing somewhat $15 \%$ dropout among girls and $4 \%$ among boys.

Article 21-A of the Constitution and the Right To Education Act which came into effect on 1 April 2010, are the compulsions in relation to which Government of India , state governments and local governments need to ensure universal education in the country. The provision of the Right to Education Act includes the words 'free and compulsory'. 'Free education' implies that no child, other than a child who has been admitted by his or her parents to a school which is not supported by the appropriate Government, shall be liable to pay any kind of fee or charges or expenses which may prevent him or her from pursuing and completing elementary education. 'Compulsory education' casts an obligation on the appropriate Government and local authorities to afford and ensure admission, attendance and completion of elementary education by all children in the 6-14 age groups. With this, India has moved forward to a rights based framework that casts a legal obligation on the Central and State Governments to implement this fundamental child right as enshrined in the Article $21 \mathrm{~A}$ of the Constitution, in accordance with the provisions of the Right to Education Act.

Chug(2011) suggests that there requires approving a holistic methodology to dropout issue and not treat it as just an isolated problem that might be embark upon without orientation to the comprehensive socioeconomic situation and meager education deliverance in which it is entrenched. Both central government and state governments need to take on preventive and restorative methods, reducing dropouts in high school education. Governments out to implement broader educational policies targeted to improve educational equity and quality with 


\section{ELK ASIA PACIFIC JOURNAL OF SOCIAL SCIENCES}

ISSN 2394-9392 (Online); DOI: 10.16962/EAPJSS/issn.2394-9392/2014; Volume 2 Issue 3 (2016)

the approval of apposite intermediation for focused groups at the local level. Based on their analysis of Analysing National Family Health Survey-3 Data, Gouda and Sekhe(2014) suggest that making improvement in the school infrastructure, education quality and making considerable investment in secondary school education may well reduce the amount of dropout to a certain extent in high schools of the country. Further they argue that unless and until there is sizable progress in the economic position of families and transformation in the social approaches of parents, accomplishing the aim of universalisation of school education will continue a main challenge for India. In a point of fact, policies and programs both at central and state governments level out to be resolving the issues concerning family and school related reasons of dropout. Family related issues are connected to broader social-economic problems therefore requires long-tern socio-economic reforms and advancement. However, as regards school related problems, governments need to review the effectiveness of current policies and programs together with approving and implementing new measures whatever need for reducing the dropout in Indian secondary education.
Vidyasagar (2015) puts forward that for reducing dropout in secondary education governments need to implement programs effects policies and programs in such a methodology so that children ought to be specified life-development skills and child's-rights skills, which will be tending to aid protect them as children. Given that dropout children turn out to be childlabourers because not having access to quality education and professional skills. Moreover, as Vidyasagar (2015) recommends policy changes are indispensable to check dropout rates and to make certain that children get lifedevelopment skills apart from developing the needed self-assurance protecting themselves from different types of exploitation. Hence, reducing dropout in secondary education is the need of the hour in a bid to protecting, nourishing and equipping children with needed skill for empowering India in terms of skilled and competent human resources.

\section{Case of Telangana and Adilabad District}

The data for 2013-14 academic year gathered across the ten districts of Telangana presents a pitiable situation of secondary education in the state in the context of school dropout rate. The most 


\section{ELK ASIA PACIFIC JOURNAL OF SOCIAL SCIENCES}

ISSN 2394-9392 (Online); DOI: 10.16962/EAPJSS/issn.2394-9392/2014; Volume 2 Issue 3 (2016)

pitiable condition is in the districts of Mahbubnagar, Medak, Warangal and Adilabad with the dropout rate of $53.21 \%$, $47.28 \%, 43.03 \%$ and $42.12 \%$ (Mukaa, 2014). Even though the situation of Mahbubnagar is the worst in terms of dropout at secondary level, yet the case of Adilabad is not less pitiable. This is particularly as regards the fact that girls dropout is very high in the Adilabad district particularly because traditional culture in the rural and tribal parts of the district restrict the girls to peruse their further education , and in most cases they get married whilst entering the secondary school. As Pagadala(2012) finds as soon as the girls enter school parents start planning to get them into wedlock, and as a result dropping from school is an easy way to turn girls into a brides.

The population of Adilabad is largely dependent on farming and therefore income certainty forces parents to get their daughters married off premature. Education can play a decisive role in dallying child marriages, but girl child generally dropout from the schools indicating towards the apathy of school managements in Adilabad. Cases reveal that as soon as the girls enter school parents start planning to get them into wedlock. Dropping from school is an easy way to turn girls into a brides. By the time girls enter high schools their probability of getting married increases. Cases reveal that girls studying in high schools specifically in class VII or VII standard fail turn up after the summer vacation to their school. This makes apparent that girls have been married off. In a few cases girls return to school post wedding, but their probability of dropping out is higher. On greater level parents and people in Adilabad are of the belief that girls are born to get married, and the cultural norms state that girls are in charge for family or household tasks, and that education is not for them (Pagadala, 2012).

Umadevi and Kiran (2015) have conducted a fresh study investigating school dropouts in two of the most backward districts in Indian state Telangana namely Mahabubnagar and Adilabad having literacy of $55.04 \%$ and $61.01 \%$ respectively. The study clearly reveals that approximately 24 $\%$ out of school students are found dropping out due to moving with their parents who migrated in look out for better jobs. The shocking revelation of the study is that somewhat $21 \%$ dropout cases are those students leave school in order to make income for their families. The study as well draws our attention towards some other 


\section{ELK ASIA PACIFIC JOURNAL OF SOCIAL SCIENCES}

ISSN 2394-9392 (Online); DOI: 10.16962/EAPJSS/issn.2394-9392/2014; Volume 2 Issue 3 (2016)

reasons of dropouts and they are mainly the requirement at home for taking care of their younger siblings and not having interest in studying accounting total $14 \%$ of the total students. There are some other notable points as revealed by the study. First of all, none of the children was found poor health condition as the reason due to dropping out of school. In the study, it is as well found that a big number of students listed as enrolled in schools by the government are in reality dropouts, making an enormous discrepancy between the data presented by the government and the real situation. Taken as a whole, in the case of Mahabubnagar and Adilabad districts of Telangana state, the study makes apparent that approximately half of the students or $46.4 \%$ enrolled in school ends as drop out. The inference of findings of study conducted by Umadevi and Kiran (2015) is that the findings are in line with findings obtained by the studies conducted on all India level, specifically in the context of reasons of school dropout mainly when it comes to family reason mainly the reason dropout from school of children for contributing in the family income.

Specifically in the case of Adilabad district migration appears to be main cause of school dropout. In the case of dropout of girl children majority of them are engaged in domestic works and for looking after the children.

Specifically in the case of tribal children, Singh (2015) finds that bullying, which is a practice of ragging in tribal welfare educational institutions, is a main reason of the higher rate of dropouts among Adivasi schoolchildren in Adilabad. Based on his findings Singh (2015) argues that since hundreds of young tribal children carry on to keep away from schools notwithstanding the good facilities being made available by the government, the issue requires a comprehensive investigation. The number of children of particularly from vulnerable tribal groups being far less than the schools capacity of the schools, children from even plains tribes are accommodated in these schools situated at Adilabad and this requires to be investigated considering the high dropout rate in the secondary education and the likely solutions at the levels of school, society and the government.

\section{Government Policies and Programs}

The government ought to develop clear principles for monitoring children at risk of dropping out, and develop mechanisms to warrant related authorities carry out social mapping, particularly in marginalized 


\section{ELK ASIA PACIFIC JOURNAL OF SOCIAL SCIENCES}

ISSN 2394-9392 (Online); DOI: 10.16962/EAPJSS/issn.2394-9392/2014; Volume 2 Issue 3 (2016)

communities and get involved making certain that children who are dropping out from school might return. Moreover, it is marked that greatness of poverty is a significant factor accountable for dropout of children in school. Besides want of local earning breaks for grown-ups put an effect on the children dropout due to migration. The State Government of Telangana is failing to resolve these problems relating to school dropout and as a result the situation is truing from worse to worst. Therefore it would be suggestive for the government in order to reduce the secondary school dropout immediate measure should be taken as regards the identified problems.

Like other states Telengana is too being supported by the Government of through the scheme of supplying mid-day meal to students of Classes I-VIII, and the State Government of Telangana from its own funds extend the scheme for classes IX and $\mathrm{X}$. noticeably the State Government is as well affording Egg / Banana twice a week to improve the nutritional standards of the students. Moreover, Mid-Day Meal is being served with super fine rice to every state in the state. 30.44 lakh students have been covered under the Mid-Day Meal scheme during 2014-15 in Telangana (ManaPSC, 2016). Despite these all programs the state is failing to reduce dropout in schools particularly in high schools. The study conducted by Pratham makes it apparent that these programs are failing to control dropout particularly in the rural areas of Telangana, and this is because of the children engagement in agriculture and related activities, particularly during harvest season. Nevertheless, interventions started by management to bring children out of school children into schools have worked, where in the case of bringing back girl students the state government needs to make provisions of gender specific facilities in schools and furthermore the examination system ought to be strengthened(ManaPSC, 2016).

Recently in the Assembly the State Government of Telangana has presented a white paper mentioning every program and achievement in the State relating to education and even talk about several curative measures for solidifying education system in the State. The State Government as well plans to work on an agenda with the aim of bring every education institution to a joint authority with a title of $\mathrm{KG}$ to $\mathrm{PG}$. However, as the Hans India Report (2016) reveals the new Government in the state is taking no notice of the general soul of the Right to Education Act. This is evident in 


\section{ELK ASIA PACIFIC JOURNAL OF SOCIAL SCIENCES}

ISSN 2394-9392 (Online); DOI: 10.16962/EAPJSS/issn.2394-9392/2014; Volume 2 Issue 3 (2016)

the fact that the Government fails to look at the benefits of rural poor children through taking the perspective of $25 \%$ seats in private schools and its implications on government schools. The report clearly reveals that the State Government of Telangana is entirely taking no notice of the main provisions of Right to Education Act for the children from entitlements and affording quality education for all. Pitiable education criterions amongst children centered schooling is evident everywhere. The report reveals the state government has no major focus primary and secondary education resulting high dropout in both the cases. There is pitiable condition of school management everywhere which further worsens situation of dropout. Due to the negligence of school management there is completely lacking in terms of establishing relationship between school and community and further Anganwadi, school and community. Based on the findings of the report and the best programs and practices in other parts of the country, the report suggests that in order to improve the education and schooling management and reduce dropout rate in Telangana, special focus ought to be on improving learning standards amongst the children, teachers should be trained with more knowledge and competences and further special measures ought to be taken for protecting girls from orthodox culture, and as well as helping out families. Even though the Hans India Report has been conducted on overall state level in Telengana, but the case Adilabad in the true reflection of pitiable educational management and programs resulting in high dropout. Therefore, governmental authorities and school management in Adilabad need to serious and with immediate effect implement the recommendations made by the report to reduce dropout in high schools of the district.

\section{Conclusion and Recommendations}

In Indian education system, dropout is a universal problem, spread over every level of education, in the entire country and across every socio-economic group of populace. However, in educationally backward states and districts the dropout rates are much higher. Besides, girls' dropout rates are found rather higher than the boys in India Dropout in secondary education is alarming in India. Reducing dropout in secondary education is the need of the hour in a bid to protecting, nourishing and equipping children with needed skill for empowering India in terms of skilled and competent 


\section{ELK ASIA PACIFIC JOURNAL OF SOCIAL SCIENCES}

ISSN 2394-9392 (Online); DOI: 10.16962/EAPJSS/issn.2394-9392/2014; Volume 2 Issue 3 (2016)

human resources. Telangana has the higher dropout rates amongst other Indian states, given that the state is one of the most backward regions in the country. Girls' dropout is very high in the Adilabad district particularly because traditional culture in the rural and tribal parts of the district restrict the girls to peruse their further education, and in most cases they get married whilst entering the secondary school. Precisely in the case of Adilabad district migration appears to be main cause of school dropout. In the case of dropout of girl children majority of them are engaged in domestic works and for looking after the children. The number of children of mostly from vulnerable tribal groups being far less than the schools capacity of the schools, children from even plains tribes are accommodated in these schools situated at Adilabad and this requires to be investigated considering the high dropout rate in the secondary education and the likely solutions at the levels of school, society and the government. The State Government of Telangana is failing to tackle these problems relating to school dropout and as a result the situation is truing from worse to worst. Therefore it would be suggestive for the government for reducing the secondary school dropout immediate measure ought to be taken as regards the identified problems. Nonetheless, steps initiated by the school management to bring children out of school children into schools have worked, where in the case of bringing back girl students the state government needs to make provisions of gender specific facilities in schools and besides the examination system ought to be strengthened. Because of the negligence of school management there is completely lacking in terms of establishing relationship between school and community and further Anganwadi, school and community. In order to improve the education and schooling management and reduce dropout rate in Telangana, special focus ought to be on improving learning standards amongst the children, teachers should be trained with more knowledge and competences and further special measures ought to be taken for protecting girls from orthodox culture, and as well as helping out families. This review paper has been made conducting only secondary research. the findings of the study can be improved conducting primary research taking sample of secondary schools located in the most backward and tribal regions of the state. 


\section{ELK ASIA PACIFIC JOURNAL OF SOCIAL SCIENCES}

ISSN 2394-9392 (Online); DOI: 10.16962/EAPJSS/issn.2394-9392/2014; Volume 2 Issue 3 (2016)

\section{References}

[1] Alagusundaram, B., Sivakumar, S. and Rajendraprasad, M.(2015), Factors Influencing of Rural Dropouts in High School Level, INDIAN JOURNAL OF APPLIED RESEARCH Volume : 5 | Issue : 10 | October 2015

[2] Chug, S.(2011), Dropout in Secondary Education: A Study of Children Living in Slums of Delhi, National University of Educational Planning and Administration, Occasional Paper, 37

[3] Gouda, S. and Sekhe, T.V.(2014), Factors Leading to School Dropouts in India: An Analysis of National Family Health Survey-3 Data, Journal of Research \& Method in Education, Volume 4, Issue 6 Ver. III (Nov - Dec. 2014), PP 75-83

[4] Hans India(2016), Note on RtE Compliances inTelanganahttp://m.dailyhunt.in/ne ws/india/english/the-hans-indiaepaper-hans/note-on-rtecompliances-in-telangana-newsid51816946
[5] ManaPSC(2016), Social development Status in Telangana201516http://www.manapsc.com/socialdevelopment-status-in-telangana-2015-16/

[6] Pagadala, T.(2012), Wedding Belles: The child brides of Adilabad, http://www.thealternative.in/society/t he-child-brides-of-adilabad/

[7] Umadevi , L. and Kiran, V.K.(2015), Telangana: Poverty hinders education, Deccan Chronicle, November 23, 2015

[8] Vidyasagar, R.(2015), School Dropout Rate High Despite Efforts by States: Expert, The New Indian Express, March 31, 2015

[9] Weber, J.M. (1988),Dropout rates for students in different high school curricula-Another look. Journal of Vocational Educational Research, 1988:13(1): 35 - 47 
APPENDIX

\section{DROPOUT RATE AT SEGONDARY LEVEL (I-X) 2013-14}

ANDHRA

TELANGANA

\begin{tabular}{lllll}
\hline DISTRICT & RATE IN PC & DISTRICT & RATE IN PC \\
\hline Srikakulam & 15.64 & Adilabad & 42.12 \\
Vizianagaram & 34.20 & Nizamabad & 32.05 \\
Vishakapatnam & 19.94 & Karimnagar & 28.42 \\
East Godavari & 17.55 & Medak & 47.28 \\
West Godavari & 9.98 & Hyderabad & 34.81 \\
Krishna & 15.42 & Ranga Reddy & 26.02 \\
Guntur & 27.82 & Mahbubnagar & 53.21 \\
Prakasm & 37.79 & Nalgonda & 42.22 \\
Nellore & 29.40 & Warangal & 43.03 \\
Kadapa & 36.64 & & Khammam & 28.10 \\
Kurnool & 45.02 & & AVERAGE & $\mathbf{3 8 . 2 1}$ \\
Anantapur & 29.71 & & 38 PG GHIILDREN DO NOT \\
Chittoor & 21.97 & & REAGH SSC LEVEL AND THUS \\
\cline { 1 - 2 } AVERAGE & $\mathbf{2 6 . 8 3}$ & & LACK BASIC EDUCATION \\
& & & &
\end{tabular}

Source: Mukaa (2014) 
ELK ASIA PACIFIC JOURNAL OF SOCIAL SCIENCES

ISSN 2394-9392 (Online); DOI: 10.16962/EAPJSS/issn.2394-9392/2014; Volume 2 Issue 3 (2016)

Educational Statistics 2013 - 2014

\begin{tabular}{|c|c|c|c|c|c|c|c|c|c|c|}
\hline \multicolumn{11}{|c|}{ Drop out Rate at Secondary Level (1-X) - 2013-14 - AL } \\
\hline \multirow{2}{*}{ SI. No. } & \multirow{2}{*}{ District } & \multicolumn{3}{|c|}{ Enrolment in class - I in 2004-2005 } & \multicolumn{3}{|c|}{ Enrolment in Classes - $\mathrm{X}$ in 2013-14 } & \multicolumn{3}{|c|}{ Drop out Rate } \\
\hline & & Boys & Girls & Total & Boys & Girls & Total & Boys & Gints & Total \\
\hline 1 & Adilabad & 31664 & 29739 & 61403 & 17764 & 17773 & 35537 & 43.90 & 40.24 & 42.12 \\
\hline 2 & Nizamabad & 27489 & 25691 & 53180 & 18448 & 17687 & 36135 & 32.89 & 31.15 & 32.05 \\
\hline 3 & Karimnagar & 41598 & 39270 & 80868 & 28722 & 29163 & 57885 & 30.95 & 25.74 & 28.42 \\
\hline 4 & Medak & 39835 & 38020 & 77855 & 21047 & 19995 & 41042 & 47.16 & 47.41 & 47.28 \\
\hline 5 & Hyderabad & 44481 & 44083 & 88564 & 27659 & 30073 & 57732 & 37.82 & 31.78 & 34.81 \\
\hline 6 & Rangareddy & 57716 & 53997 & 111713 & 42580 & 40064 & 82644 & 26.22 & 25.80 & 26.02 \\
\hline 7 & Mahbubnagar & 52335 & 49456 & 101791 & 24786 & 22843 & 47629 & 52.64 & 53.81 & 53.21 \\
\hline 8 & Nalgonda & 43731 & 41146 & 84877 & 25271 & 23773 & 49044 & 42.21 & 42.22 & 42.22 \\
\hline 9 & Warangal & 48034 & 45507 & 93541 & 27262 & 26028 & 53290 & 43.24 & 42.80 & 43.03 \\
\hline 10 & Khammam & 24428 & 23342 & 47770 & 17164 & 17185 & 34349 & 29.74 & 26.38 & 28.10 \\
\hline & Total & 411311 & 390251 & 801562 & 250703 & 244584 & 495287 & 39.05 & 37.33 & 38.21 \\
\hline
\end{tabular}

$:=71:=:$

Source: Educational Statistics(2015) Educational Statistics Telangana 